\title{
Review
}

Journal of Innate

Immunity
$\mathrm{J}$ Innate Immun 2010;2:96-106

DOI: $\underline{10.1159 / 000243784}$
Received: June 30, 2009

Accepted after revision: August 5, 2009

Published online: October 1, 2009

\section{A New Danger in the Air: How Pulmonary Innate Immunity Copes with Man-Made Airborne Xenobiotics}

\author{
E.A. Lanckacker ${ }^{a}$ L.J. Robays ${ }^{b} \quad$ G.F. Joos ${ }^{a}$ K.Y. Vermaelen ${ }^{a, c}$ \\ ${ }^{a}$ Department of Respiratory Medicine, Ghent University Hospital, Ghent, ${ }^{b}$ Laboratory of Molecular and \\ Cellular Therapy, Department of Physiology and Immunology, Medical School of Vrije Universiteit Brussels, Brussels, \\ and ${ }^{\mathrm{C}}$ Laboratory of Immunoregulation and Mucosal Immunology, Ghent University, Ghent, Belgium
}

\section{Key Words}

Aryl hydrocarbon receptor - Dendritic cells · Diesel • Inflammation $\cdot$ Innate immunity $\cdot$ Lung $\cdot N F K B$ signaling $\cdot$ Oxidative stress

\begin{abstract}
The pulmonary innate immune system has evolved over millions of years to provide swift detection of inhaled microbial agents and trigger well-balanced protective responses. Much more recent on the evolutionary scale is human activity, which has resulted in the release of a new class of potentially harmful, non-microbial compounds into the air. These xenobiotics include combustion by-products such as reactive oxygen species and polycyclic aromatic hydrocarbons. This review will summarize evidence showing how airborne xenobiotics can engage pulmonary innate immunity components at many levels. We will focus on potential effects of xenobiotics on airway dendritic cells, as these constitute key innate immune sensors in the lung, with the unique ability to initiate adaptive immunity. We propose that the aberrant processing of inhaled xenobiotics by an innate immune system that is now evolutionarily maladapted underlies the increase in chronic inflammatory lung diseases in modern times.

Copyright $\odot 2009$ S. Karger AG, Basel
\end{abstract}

\section{Ancient Meets Novel: Pulmonary Innate Immunity and the Rise of Anthropogenic Airborne Compounds}

The innate immune system of the lung is one of the most critical homeostatic systems in the body. Lifethreatening damage to the delicate gas-exchange structures can occur either by failure to rapidly detect and clear inhaled airborne pathogens, or as a result of an unbridled inflammatory response.

Pulmonary innate immune defenses consist of several interacting components [1]. The integrity of the epithelial layer and the mucociliary transport system form a first mechanical barrier in the conductive airways. Surfactant proteins, synthesized by the epithelium of the deeper alveolar zones, bear structural analogy to serum complement and constitute an additional immediate defense mechanism [2]. Phagocytic cells, such as macrophages and neutrophils, complete the picture by neutralizing persistent inhaled pathogens. Invariant NK T cells and dendritic cells (DCs) are also important innate immune sensors in the lung, with the latter being unique in their ability to initiate primary adaptive immune responses. Both structural cells (epithelium) and leukocyte components of the pulmonary innate immune system are equipped with pathogen recognition receptors, i.e. Toll-

\section{KARGER \\ Fax +4161306 1234 \\ E-Mail karger@karger.ch}

www.karger.com
(C) 2009 S. Karger AG, Basel

1662-811X/10/0022-0096\$26.00/0

Accessible online at:

www.karger.com/jin
Dr. Karim Y. Vermaelen

Department of Respiratory Medicine

Ghent University Hospital

De Pintelaan 185, BE-9000 Ghent (Belgium)

Tel. +329332 2815, Fax +329332 9476, E-Mail karim.vermaelen@ugent.be 
like receptors (TLRs), NOD-like receptors and RIG-like receptors, and they provide immediate sensing of pathogen-associated molecular patterns (PAMPs) from inhaled bacteria, viruses or fungi [3].

It can be assumed that the pulmonary innate immune system had to co-evolve with the development of lungs in the first terrestrial vertebrates, i.e. during the Devonian era some 360 million years ago. The explosive colonization of the land by the myriads of organisms that characterized that period must have brought a constant selection pressure on the very first airway innate defense mechanisms. This would have forced a repertoire diversification of pathogen recognition receptors, which were in part structural variations on a theme that also evolved in land-based arthropods (e.g. Toll-molecules in insects). Seen on this time-scale, human evolution is an extremely recent event.

Since prehistoric times, and boosted by the first industrial revolution, human activity has resulted in the ever increasing release of airborne products, which have been largely derived from the combustion of biomass and fossil fuels. Inhalational exposure to fine carbonaceous particles - such as diesel exhaust particles, as well as to a broad array of volatile molecules such as carbon monoxide, nitrogen oxides, sulfur dioxides and the potentially carcinogenic polycyclic aromatic hydrocarbons (PAHs) [4] - has increased with the growth of human communities (table 1). Even higher levels of exposure to combustion products have been reached since the widespread use of tobacco.

The purpose of this review is to examine how the immune system of the lung reacts to these evolutionary recent anthropogenic stimuli. Among the different cellular actors of pulmonary innate immunity, we will particularly focus on the network of airway dendritic cells, given their unique role as both innate immune sensors and controllers of adaptive immune responses.

\section{Airway Dendritic Cells: Specialized Immune Sensors at the Forefront of the Lung-Air Interface}

DCs are professional antigen-presenting cells capable of priming and sustaining the expansion of naïve $\mathrm{T}$ cells. They are present in tissues in close contact to the external environment, such as the skin (i.e. Langerhans cells), mucosal surfaces of the upper and lower airways, and the gastro-intestinal and urogenital tracts. In the lung, DCs are located as a network immediately above and beneath the basement membrane of conductive airways, as well as within the interalveolar septa of the deeper lung parenchyma [5]. In the steady state, airway DCs can project their dendrites in between epithelial cells without breaking the epithelial layer integrity and sample the epithelial lining fluid which is in direct contact with the inhaled air [6]. DCs are equipped with specialized receptors (e.g. Ctype lectin receptors, TLRs) for antigen capture and for sensing PAMPs and danger-associated molecular patterns, the latter being released as a result of tissue damage (whether as result of microbial invasion or not) [7]. Inhalational exposure to PAMPs unveils the innate character of airway DC dynamics, as reflected by a fast and massive recruitment of these cells into the airways, being at least as rapid as the prototypical neutrophilic influx [8]. Capture of inhaled antigen in the presence of PAMPs and/or danger-associated molecular patterns leads to DC activation, which initiates a series of events leading to the adaptive immune response: stimulated migration to the $\mathrm{T}$ cell zones of draining thoracic lymph nodes, strong up-regulation of processed antigen on surface major histocompatibility molecules (MHC) and up-regulation of T cell costimulatory molecules such as CD40 and B7-1, B7-2. An emerging paradigm is that the resulting $\mathrm{T}$ cell polarization (T helper 1, 2 or 17) is likely 'programmed' as a result of DC exposure to specific molecular patterns present at the time and place of antigen encounter in the periphery. This includes both direct stimulation of DCs by pathogen-derived factors, or indirect conditioning by innate factors released by surrounding cells. As an illustration of the latter, stimulation of TLR4 on airway epithelial cells results in the production of innate cytokines (including TSLP, GM-CSF and IL-33) and secondary activation of the DC network, which in this case is conditioned to induce a $\mathrm{T}$ helper 2 polarized immune response [6].

By contrast, aero-antigen sampling in the absence of innate stimuli is followed by steady-state airway DC migration and antigen presentation in the draining lymph nodes [9], resulting in the induction of regulatory $\mathrm{T}$ cells and establishment of inhalational tolerance [10].

With these concepts in mind, the question arises whether airborne xenobiotics can act directly as innate stimuli on airway dendritic cells and, if so, how this could affect the outcome of pulmonary immune responses. In the next sections, we will highlight the effects of 2 main active components in inhaled xenobiotics on DC biology: reactive oxygen species (ROS) and PAHs. It should be stressed that insights into these mechanisms have mostly been derived from in vitro models. Hence, extrapolation to in vivo situations must be made with caution: in a more 
Table 1. Summary of the major primary and secondary air pollutants and their sources

\begin{tabular}{|c|c|c|}
\hline Air pollutant & Natural source & Anthropogenic source \\
\hline $\begin{array}{l}\text { Primary Pollutants } \\
\mathrm{SO}_{\mathrm{x}}\left(\text { e.g. } \mathrm{SO}_{2}\right) ; \text { precursors of acid rain } \\
\text { and secondary fine sulfate particles }\end{array}$ & volcanic activities & $\begin{array}{l}\text { industrial processes; fossil fuel combustion (mostly coal, } \\
\text { petroleum) in power plants and other stationary sources; } \\
\text { indoor gas burners (stoves and heaters) }\end{array}$ \\
\hline $\begin{array}{l}\mathrm{NO}_{x}\left(\text { e.g. } \mathrm{NO}_{2} \text { ); precursors of acid }\right. \\
\text { rain and visibility reducing fine nitrate } \\
\text { particles }\end{array}$ & $\begin{array}{l}\text { lightning; biological } \\
\text { processes in soil }\end{array}$ & $\begin{array}{l}\text { high-temperature combustion processes in automobiles and } \\
\text { power plants; indoor gas burners (stoves and heaters) }\end{array}$ \\
\hline $\mathrm{CO}$ & wildfires & $\begin{array}{l}\text { incomplete combustion of fuel (natural gas, coal, wood); } \\
\text { motor vehicle exhaust; fuel combustion unrelated to } \\
\text { transport; industrial processes (e.g. metal processing); } \\
\text { indoor gas burners (stoves and heaters) }\end{array}$ \\
\hline Total suspended particulate matter & $\begin{array}{l}\text { volcanic activity; dust } \\
\text { storms; grassland fires; } \\
\text { living vegetation; sea spray }\end{array}$ & $\begin{array}{l}\text { fossil fuel combustion in vehicles, power plants and industrial } \\
\text { processes; wood stoves }\end{array}$ \\
\hline $\begin{array}{l}\text { VOCs }\left(\mathrm{CH}_{4} \text {, benzene, toluene, xylene, }\right. \\
\text { petrol vapour emissions, etc.) }\end{array}$ & food digestion $\left(\mathrm{CH}_{4}\right)$ & $\begin{array}{l}\text { industrial uses; waste deposition in landfills which generate } \\
\text { methane; petrol stations; fumes from paint, hair sprays, } \\
\text { varnish, aerosol sprays, solvents utilization }\end{array}$ \\
\hline $\begin{array}{l}\text { Toxic metals (lead, cadmium, copper, } \\
\text { mercury) }\end{array}$ & & $\begin{array}{l}\text { industrial processes from metal smelters; combustion of } \\
\text { leaded gasoline, aviation fuels, etc. }\end{array}$ \\
\hline $\begin{array}{l}\text { Organic pollutants (dioxins, PAHs } \\
\text { such as benzo(a)pyrene) }\end{array}$ & $\begin{array}{l}\text { forest fires; volcanic } \\
\text { activity }\end{array}$ & $\begin{array}{l}\text { incomplete combustion of carbon-containing fuels (wood, } \\
\text { coal, diesel, fat, tobacco); combustion processes and } \\
\text { industrial processes (e.g. processing of coal, crude oil, } \\
\text { creosote, coal tar, bitumen and asphalt industries); } \\
\text { combustion of kerosene (liquid mixture of hydrocarbons) }\end{array}$ \\
\hline
\end{tabular}

\section{Secondary Pollutants}

Ground level $\mathrm{O}_{3}$ (constituent of

'photochemical' smog)

Peroxyacetyl nitrate (constituent of

'photochemical' smog)

formed from $\mathrm{NO}_{\mathrm{x}}+\mathrm{VOCs}$

Primary pollutants constitute direct emissions, whereas secondary pollutants are formed as a result of primary pollutants undergoing chemical reactions. An important example of a secondary pollutant is ground level ozone, one of the pollutants that make up 'photochemical' smog and a rich source of reactive oxygen species. VOC = Volatile organic compounds.

realistic tissue or whole-organism context, effects on DCs can also be indirect, as mentioned earlier. Co-culture models can provide additional useful information, as shown in a study involving dendritic cells incubated with bronchial epithelial cells. In this system, addition of diesel exhaust particles triggers, in an oxidant-dependent manner, epithelial release of TSLP which then activates
DCs and induces Th2 polarization [11]. In vivo animal studies aim to be more relevant to clinical observations, but are not without drawbacks either: animal exposure models such as inhalation of tobacco smoke or diesel exhaust particles involve multiple potential mediators acting simultaneously on several receptor systems on a broad range of cells, making it difficult to clearly delineate rel- 


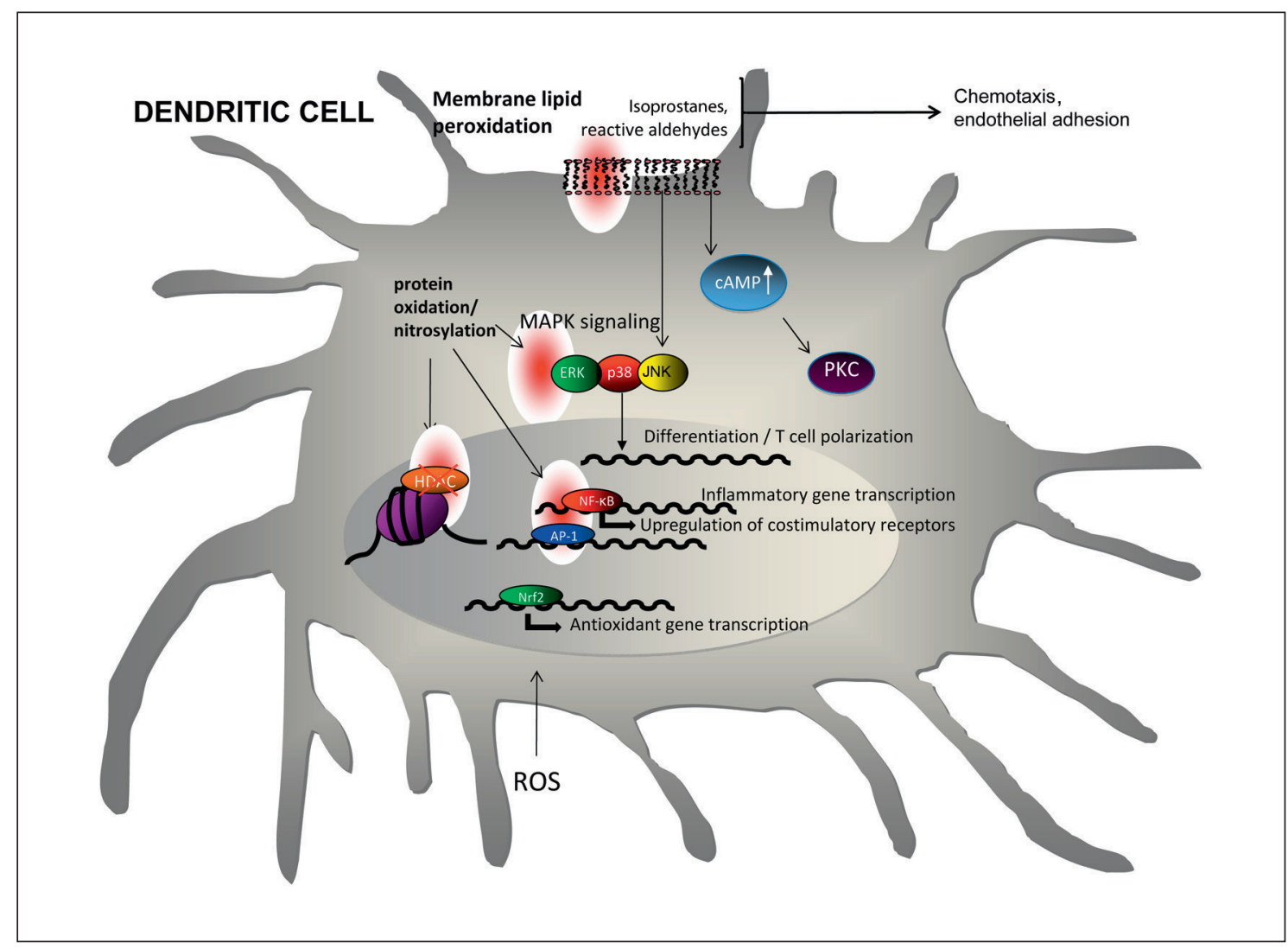

Fig. 1. Schematic overview on the cellular-molecular effects of ROS, with a special emphasis on pathways that are relevant to DC biology, such as activation of $\mathrm{NF \kappa B}, \mathrm{ERK} / \mathrm{MAPK}$ and AP-1 signaling cascades.

evant pathogenetic molecular mechanisms. For instance, both diesel exhaust particles and tobacco smoke are complex vectors for ROS, PAHs and myriads of other bioactive compounds. Moreover, diesel exhaust particles and tobacco smoke are often administered to animals in ways that do not reflect real-world situations, such as the use of excessive doses, and/or instillation of soluble extracts rather than inhalation of airborne forms [12].

\section{How Oxidative Stress Can Affect Pulmonary Dendritic Cells}

ROS are now recognized as important elements in the pathogenesis of several inflammatory disorders. ROS, which include oxygen ions, free radicals and peroxides, are highly unstable molecules with unpaired electrons, capable of initiating oxidation of cellular components. Endogenous ROS are generated by biochemical redox reactions of the natural cell metabolism including mito- chondrial respiration or the oxidative burst of phagocytic cells, whereas exposure to air pollutants is the main source of exogenous ROS [13]. Carbonaceous fine particulate matter (including diesel exhaust particles), gases such as ozone, nitrogen dioxide and sulfur dioxide are all potential sources of ROS generation at the level of airway surfaces. Not surprisingly, the lung has evolved elaborate antioxidant mechanisms to limit damage caused by ROS. ROS can affect cells at multiple levels. ROS generation in close proximity to the cell membrane oxidizes membrane phospholipids, resulting in the formation of highly reactive aldehydes such as acrolein, 4-hydroxy-2-nonenal (4HNE) and related 4-hydroxy-2,3-alkenals (HAKs) [14] (fig. 1). HNE and HAKs possess high affinity towards specific amino acid residues of intracellular proteins involved in several aspects of cell signaling, chromatin remodeling and gene transcription. For instance, $4-\mathrm{HNE}$ is capable of inducing adenylate cyclase activation, increasing cAMP levels and thus affecting cellular function by activating cAMP-dependent protein kinases [15]. Reac- 
tive aldehydes can form stable adducts with JNK1/2, leading to subsequent activation of the transcription factor activator protein 1 (AP-1) and suggesting a possible role for 4-HNE in the modulation of cell proliferation and differentiation [16]. Interestingly, 4-HNE and HAKs both possess chemotactic activity towards neutrophils and monocytes, an important aspect of innate immunity [17]. Isoprostanes are alternative by-products of membrane lipid oxidation, which are further processed into bioactive molecules, such as 1-palmitoyl-2-(5)oxovaleroyl-snglycero-3-phosphorylcholine (POVPC), 1-palmitoyl-2epoxyiso-prostane-sn-glycero-3-phosphorylcholine (PGPC) and 1-palmitoyl-2-epoxyisoprostane-sn-glycero3-phosphorylcholine (PEIPC). These molecules possess innate pro-inflammatory effects as they can activate monocyte and neutrophil adhesion to the endothelium and increase their cytokine release [18].

Protein nitration is another product of ROS-induced tissue damage. A reaction between $\mathrm{NO}$ and $\mathrm{O}_{2}^{-}$radicals results in the formation of peroxynitrite anions $\left(\mathrm{ONOO}^{-}\right)$. These are highly reactive radicals, able to nitrosylate tyrosine residues to produce the stable product nitrotyrosine. Tyrosine nitration affects the function of important intracellular proteins such as NFкB [19], MAPK [20] and HDACs [21]. In addition, oxidation of cysteine residues in the DNA binding domain of the socalled redox sensitive transcription factors (NFKB, AP-1) can have profound effects on inflammatory gene expression and cell differentiation [22]. An important redoxsensitive protein is nuclear erythroid 2 p 45 -related factor 2 (Nrf2). Oxidative stress interferes with the default cytoplasmic anchoring of Nrf2 to the cytoskeleton-associated protein Keapl. Thus freed, Nrf2 translocates to the nucleus and activates the transcription of several genes which have been shown to have antioxidant and anti-inflammatory activity in the lung [23]. Also, in homeostatic conditions Nrf2 activity is low, as a consequence of a Keapl-dependent proteosomal degradation [24].

Finally, ROS can also mediate the activation of the NALP3 inflammasome and trigger the secretion of the pro-inflammatory cytokine IL-1 $\beta$, as was shown in a model of asbestos fiber inhalation [25]. Like IL-1 $\beta$, IL-18 is produced following cleavage of a pro-form by the NALP3-activated caspase 1. Interestingly, Nrf2-deficient DCs challenged with ambient particulate matter show enhanced production of IL-18 compared to wild-type DCs [26], suggesting a possible interaction between inflammasome-dependent IL-18 generation and Nrf2 redox sensing mechanisms.
With that knowledge in mind, several groups have used in vitro systems to closely dissect the effects of ROS on key features of dendritic cell biology. Preynat-Seauve et al. [27] analyzed the effects of oxidative stress on antigen processing and $\mathrm{T}$ cell presentation and indicated that oxidative stress inhibits the capacity of antigen-presenting cells to process antigens and to initiate a primary $\mathrm{T}$ cell response. By contrast, a study by Kantengwa et al. [28] demonstrated a ROS-induced early maturation of human monocyte-derived DCs, characterized by a clear up-regulation of costimulatory molecules (CD80, CD83 and CD86) and a decrease in endocytic activity. Likewise, it was shown that exposure of DCs to $\mathrm{H}_{2} \mathrm{O}_{2}$ induces upregulation MHC II and costimulatory molecules (CD40, B7-2). Accordingly, $\mathrm{H}_{2} \mathrm{O}_{2}$-conditioned DCs were more efficient in promoting $\mathrm{T}$ cell proliferation than non-treated DCs [29]. These findings link ROS production and subsequent tissue damage to the innate activation of DCs and the initiation of adaptive immune responses. The involvement of oxidative stress mechanisms in DC activation and cytokine secretion includes a significant increase in protein oxidation, measured by the formation of carbonyl radicals, and triggers p38 and extracellular signal-regulated mitogen-activated protein kinase (ERK/ MAPK), resulting in the up-regulation of CD40 [30]. Thus, MAPK, which was described earlier as an important mediator of DC maturation following innate immune stimuli [31], appears to be an important target of ROS attack in itself. The exquisite sensitivity of DCs to oxidative influences is further illustrated by a study showing how treatment with anti-oxidants can virtually paralyze the NFкB, MAPK and PKC response following innate inflammatory stimuli such as LPS or IL-1 $\beta$. Interestingly, this led to the preferential induction of regulatory $\mathrm{T}$ cells by the DCs [32]. In the same line, Vassallo et al. [33] showed that the high production of the neutrophil chemoattractant CXCL 8 by in vitro tobacco smoke-conditioned DCs and ex vivo DCs isolated from tobacco smoke-exposed mice can be suppressed by the use of the antioxidant $\mathrm{N}$-acetyl-cysteine. In contrast to these observations, Kroening et al. [34] demonstrated that activation of ERK-dependent pathways in DCs by oxidative stress from soluble cigarette smoke components potently inhibits the production of IL-12 and IL-23 by mature DCs.

Further reinforcing the notion that ROS may promote DC-dependent pro-allergic responses, Williams et al. [26] showed exacerbated DC maturation, inflammatory cytokine secretion and Th2 polarization in Nrf2-deficient DCs exposed to particulate matter-associated ROS. This was consistent with a study by the same group show- 
ing that Nrf2-deficient mice develop more severe features of allergic airway inflammation in an ovalbumin sensitization/challenge model than wild-type controls [35].

The contrasting results of ROS and DC response investigations are an inevitable consequence of the reductionist nature of the experimental models and reflect the complex nature of oxidative stress effects on living cells. ROS-sensitive epigenetic modulation of gene expression adds another layer of complexity to the impact of oxidative stress on DCs. An important element of epigenetic regulation is post-translational modification of histones by histone acetylases and deacetylases (HDACs), whereby histone deacetylation results in compact winding of chromatin, obstructing access to transcription factors and suppressing gene transcription [36]. As mentioned earlier, HDACs are a target of ROS attack by means of lipid peroxidation products or tyrosine residue nitrosylation. ROS can inactivate certain histone deacetylases (HDAC$2,-5$ and -8 ) to promote the expression of pro-inflammatory genes in a number of pulmonary cells [37]. Interestingly, HDACs are increasingly recognized as important regulators of innate immune responses and of DC function in particular, as illustrated by several studies. For instance, pharmacological HDAC inhibition (by the synthetic compound LAQ824) can alter TLR-4-dependent activation of macrophages and DCs and suppress Th1but not Th2-cell activation and migration [38]. In a different study, it was shown that HDAC inhibition decreases TLR-mediated activation of proinflammatory gene expression, due to impaired transcription factor recruitment [39]. HDAC inhibition also changes DC differentiation by affecting the expression of costimulatory and adhesional molecules. The HDAC inhibitor butyrate inhibits the expression of CD1 molecules, but not CD83, CD86 and MHCII molecules, and butyrate-treated immature DCs showed lower production of IL-12 and IL-6 [40]. The observed defects in DC function after HDAC inhibition seem to rely on impaired nuclear translocation of $\mathrm{NFKB}$, IRF-3 and IRF-8 [41]. Thus, ROS-induced defects in HDAC activity could have profound effects on normal innate responses of pulmonary DC, just as it does on other cells in the lung.

Recently, an intriguing report was published pointing to a fundamental role of Toll-like receptors as alternative sensors for exogenous oxidants in the lung. The study by Paul-Clark et al. [42] clearly identified TLR2, but not TLR4, as an important receptor mediating the production of CXCL8 after exposure to soluble oxidants. This may shed a new light on the finding by our group that tobacco smoke-induced airway inflammation, pulmo-

Pulmonary Innate Immunity and

Man-Made Airborne Xenobiotics nary DC recruitment and DC activation occur in a TLR4dependent fashion [43]. In an in vivo mouse model of tobacco smoke inhalation, we observed a marked up-regulation of MHC II and the costimulatory molecules CD40 and B7-2 on airway DCs, and this effect was profoundly impaired in TLR4-deficient mice. In vivo studies from a different group have raised doubts whether the TLR4-dependent effects of tobacco smoke are due to the well-documented presence of endotoxin [44]. Consequently, the link between ROS exposure and TLR signaling may offer an attractive alternative explanation.

\section{Polycyclic Aromatic Hydrocarbons as a Separate Class of Innate Stimuli for Dendritic Cells}

Airborne PAHs are mainly by-products of industrial activity and domestic combustion processes, such as woodfire heating, tobacco smoking and cooking. Diesel exhaust particles are another important carrier of PAHs. Because PAHs are highly resistant to metabolic breakdown, they tend to accumulate in the body, hence further extending exposure time and increasing the risk for a broad range of adverse health effects that include carcinogenesis, immunotoxicity and endocrine dysregulation. PAHs, which include dioxin-like compounds, have toxic effects that are mediated by the aryl hydrocarbon receptor (AhR) [45]. This is a ligand-dependent basic helixloop-helix transcription factor involved in the regulation of xenobiotic metabolism and detoxification. The evolutionarily highly conserved structure of the AhR suggests interactions with endogenous ligands. This is illustrated by functions which are unrelated to detoxification of modern environmental xenobiotics [46], including vascular development, regulation of circadian rhythm and modulation of immune responses, as discussed below. In the inactivate form, the AhR is a soluble cytosolic protein, forming a complex with chaperone proteins, heat shock protein 90 and an immunophilin-like protein called XAP2 (fig. 2). Both chaperone proteins bind to the AhR nuclear localization sequence, preventing the inappropriate trafficking of the receptor into the nucleus. Upon ligand activation, the XAP2 protein dissociates from the $\mathrm{AhR}$, resulting in the exposure of the nuclear localization sequence and subsequent translocation to the nucleus. Once in the nucleus, the AhR dissociates from heat shock protein 90 and dimerizes with ARNT (AhR nuclear translocator) to reconstitute an active transcription factor. The AhR-ARNT complex binds to specific DNA response elements known as dioxin-responsive elements or

Innate Immun 2010;2:96-106 


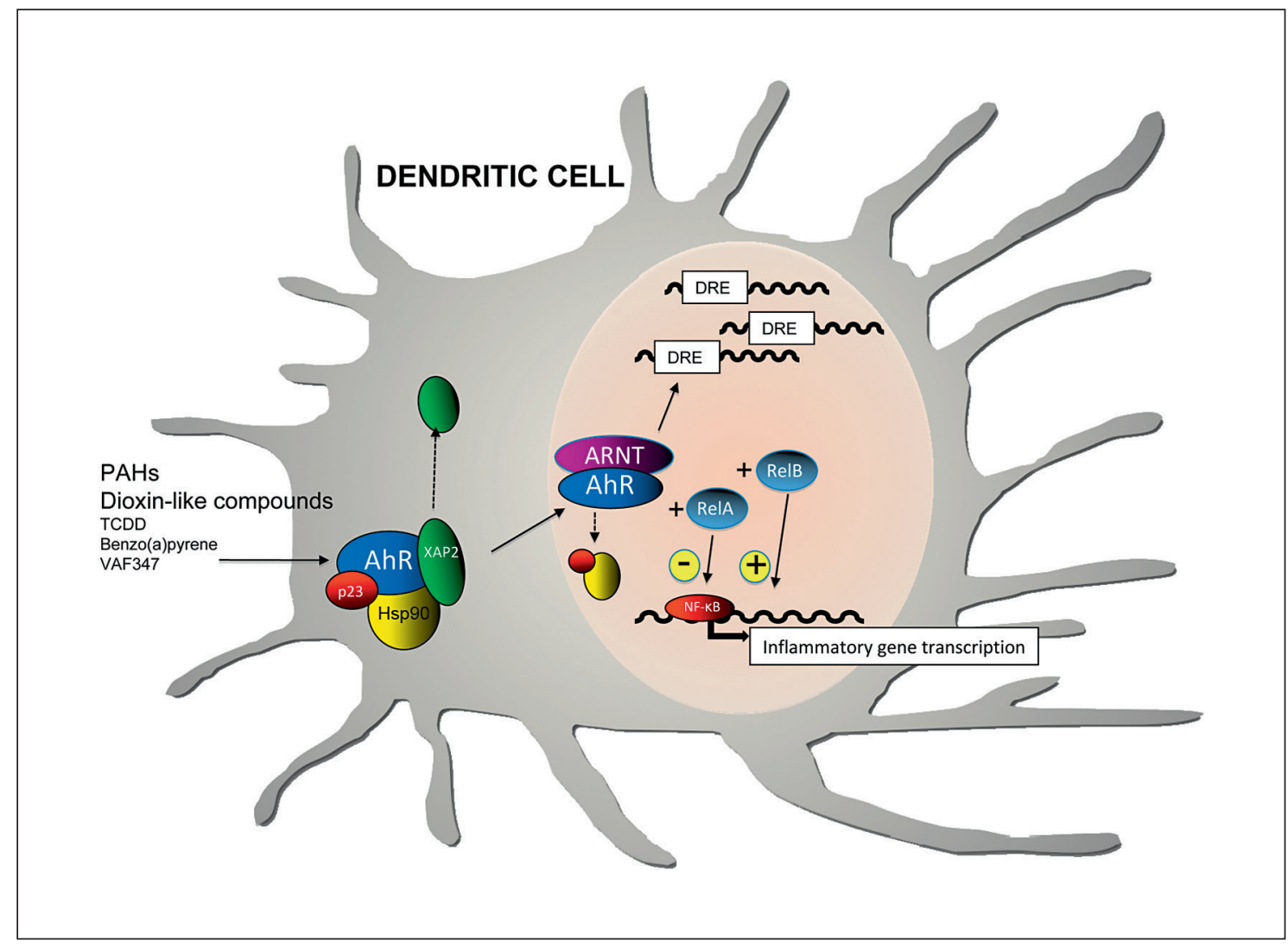

Fig. 2. Hypothetical effects of aryl hydrocarbon receptor signaling in DCs. A central element is the dual nature of interactions of AhR with components of the NFKB signaling cascade, the latter being essential for DC activation following innate stimuli and the acquisition of $\mathrm{T}$ cell immunostimulatory power. Probably depending on the ligand, AhR engagement can engage different subunits of NFkB complexes and lead to both suppression or induction of inflammatory gene expression. DRE = Dioxin-responsive elements.

xenobiotic responsive elements. Dioxin-responsive elements are present in many promotors and drive transcription of a wide range of genes, not only for xenobiotic metabolism (i.e. induction of cytochrome family of proteins), but also genes involved in the regulation of cell differentiation, proliferation and activation [47].

There is growing evidence pointing to an active role of the AhR signaling pathway in immune responses [46]. Engagement of the AhR leads to diverse, sometimes opposing immunological effects depending on ligand binding characteristics as well as the broader cellular and molecular environmental context. Exposure to TCDD (2,3,7,8-tetrachlorodibenzo-p-dioxin), a prototype of $\mathrm{PAH}$ with high affinity to the AhR, can lead to both proinflammatory effects with the induction of TNF- $\alpha$, IL- $1 \beta$ COX-2 and IL-8 [48-50] or suppression of adaptive immunity. TCDD-dependent activation of the AhR can in- duce suppression of $\mathrm{B}$ and $\mathrm{T}$ cell-dependent responses and result in increased susceptibility to infection [51]. A series of in vivo studies have highlighted the complex effects of AhR-triggering in the setting of influenza infection, a suitable model to illustrate the shift from innate immunity to adaptive response in the lung (reviewed in [52]). The innate response characterized by neutrophilia and interferon production is amplified in TCDD-treated, infected mice, while the clonal expansion of virus-specific CD8 T cells is profoundly suppressed. Interestingly, the latter phenomenon appears indirect, as CD8 T cells from $\mathrm{Ahr}^{-/-}$animals are still prone to suppression when transferred into $\mathrm{Ahr}^{+/+}$hosts [53]. This suggests that the defect in adaptive immune response after AhR triggering occurs at the level of the accessory cell, i.e. most probably targeting the DC itself. Several in vitro studies have further highlighted the immunosuppressive effects of AhR 
ligands. Benzo(a)pyrene (BP) has been reported to impair antigen presentation by mouse macrophage and alters the T cell-macrophage interaction [54]. Similarly, PAHs can impair differentiation of blood-derived monocytes into functional macrophages [55].

When it comes to dendritic cells specifically, direct effects of PAHs are similarly complex, often producing contradicting reports. Jux et al. [56] provided evidence for a physiological role of the AhR in Langerhans cells (LCs), the predominant DC population of the epidermis. They observed an impaired up-regulation of costimulatory molecules in TCDD-stimulated, AhR-deficient murine LCs compared to AhR-competent LCs, and consequently an impaired induction of contact hypersensitivity. Interestingly, the $\mathrm{AhR}$ was also necessary for the up-regulation of indoleamine-2,3-dioxygenase (IDO) expression in DCs. IDO enzymatic activity in DCs is known to result in $\mathrm{T}$ cell anergy or the generation of regulatory $\mathrm{T}$ cells [56].

Laupeze et al. [57] studied the effects of PAHs on the differentiation, maturation and biological function of human monocyte-derived DCs in vitro. Exposure of monocytes to BP during their development into DCs resulted in impaired up-regulation of DC-specific differentiation and maturation markers such as CD1a, CD80 and CD40. Moreover, DCs generated in the presence of BP displayed decreased endocytic activity and showed impaired IL-12 secretion. BP-exposed DCs poorly stimulated $\mathrm{T}$ cell proliferation compared to their untreated counterparts [57]. In a recent report, Platzer et al. [58] further highlight the suppressive effects of AhR triggering on DC biology. Using the synthetic AhR ligand VAF347, they reveal the involvement of the AhR in suppressing commitment of human myeloid progenitors towards the monocyte/DC lineage. In a different report, VAF347 also appears capable of inhibiting the up-regulation of MHCII and B7-2 on DCs [59]. In the same line, Hwang et al. [60] showed that the AhR ligand benzopyrene inhibits the growth and functional differentiation of mouse bone marrow-derived DCs. BP induced little alterations in CD11c, MHCII and CD86 surface expression, but clearly impaired production of IL-12, IL-10 and TNF- $\alpha$ as well as allogeneic T cell-stimulating ability. This was accompanied by a reduced expression of the RelB NFKB protein family member, which is known to be pivotal for DC differentiation and function [60]. Even though BP and the dioxin-like TCDD are both ligands of the AhR, their effects on the development and function of DCs can be divergent. This is illustrated by a study in which TCDD-treated DCs expressed signifi- cantly higher levels of DC differentiation markers such as MHCII and the co-stimulatory molecule CD86, impaired IL-10 and intact IL-12 production. Accordingly, $\mathrm{T}$ cell stimulatory capacity was increased in TCDDtreated compared to control DCs [61]. Also Vogel et al. [62] showed increased maturation of human monocytederived DCs after AhR activation by TCDD, as manifested by characteristic morphological changes and upregulation of costimulatory molecules. Again, AhR triggering by TCDD in DCs led to induction of IDO expression and enzymatic activity. A similar effect of AhR triggering was observed in vivo, with increased IDO expression in the lungs and spleen of TCDD-treated mice, resulting in the induction of FoxP3 transcripts (implicating an increased differentiation of regulatory T cells) [62].

Insights into the divergent effects of PAHs on DCs came with the discovery that the AhR is involved in a complex cross-talk with several members of the NFкB pathway. Specifically, AhR can dimerize with RelA and antagonize the canonical NFкB pathway, leading to suppression of inflammatory gene expression. At the same time, the AhR can form a complex with RelB and in some cases enhance transcription of inflammatory cytokines and chemokines [63], or presumably affect functional features of DCs which rely on non-canonical NFкB activation (e.g. antigen cross-presentation) [64]. Which downstream signaling pathway will be activated following binding of a specific AhR ligand will likely depend on concomitant innate stimuli, as well as the differentiation/ maturation state of the DC target.

\section{From Airborne Xenobiotic Exposure to Pulmonary Immunopathology: The Dendritic Cell Link?}

Given their anatomical distribution, airway DCs constitute inevitable targets of inhaled xenobiotics. Because innate receptors of DCs did not evolve under selective pressure from anthropogenic compounds, it can be assumed that confrontation of airway DCs with these agents will initiate aberrant pulmonary immune responses, or modulate the outcome of classical anti-microbial defenses. This working hypothesis may shed new light on the pathogenesis of several chronic inflammatory pulmonary diseases. A good illustration is the implication of tobacco smoke exposure in the development of asthma. Tobacco smoke inhalation activates multiple mechanisms that can potentially program DCs to polarize proallergic $\mathrm{T}$ helper 2 type responses towards co-inhaled an- 
tigen. Tobacco smoke is a known vector for endotoxinlike compounds, the latter having been implicated in the induction of Th2 responses [65]. Despite this fact, our group has recently shown unimpaired development of tobacco smoke-induced allergic sensitization in TLR4 and Myd88 gene-deficient mice [66]. This suggests alternative Th2-promoting effects of tobacco smoke on DCs, such as ROS-induced activation of the MAPK/ERK pathway [34], or the secondary release of Th2-promoting innate factors such as TSLP, ATP or IL-33 [67].

Another illustration of pulmonary immunopathology with a strong link to human activity is COPD, a chronic pulmonary disease associated with the inhalation of tobacco smoke and, presumably, biomass combustion products in general. Among the many xenobiotics present in smoke, the dual effects of PAHs as both promoting chronic inflammation, while simultaneously suppressing adaptive immunity, may contribute to the relentless progression of pulmonary damage, coexisting with the enhanced sensitivity to infection that characterizes COPD. This is reflected in the specific changes in airway DC populations observed in COPD patients, i.e. increased recruitment of airway epithelial DCs (a sign of innate pro-inflammatory response), which, however, display an immature phenotype [68]. COPD is clearly a disease of aberrant immunostimulation in the lung, and it is very likely that the reprogramming of pulmonary DCs by smoke-derived xenobiotics plays a central role in perpetuating the chronicity of the inflammation, even after smoking cessation. Epigenetic reprogramming of DCs is an interesting hypothesis to explain the hard-wiring of this aberrant response. In support of this, extensive studies have unveiled progressive reduction in HDAC activity in COPD bronchial biopsies, a phenomenon that was proportional to COPD severity. Specifically, HDAC activity was suppressed in alveolar macrophages from COPD patients, resulting in enhanced and glucocorticoisteroid-resistant production of innate pro-inflammatory cytokines [37]. It is very likely that airway DCs are subject to similar epigenetic modulations, probably under influence of ROS, as detailed above. In contrast to the innate scavenger function of alveolar macrophages, the impact of these effects on DCs is more far-reaching, as DC function can shift from innate immune sensor to initiator of adaptive immunity, with the potential to instruct tolerance versus active immune response. Accordingly, reports have recently emerged suggesting the presence of an aberrant adaptive response in COPD, including reactivity against self-antigens within the lung tissue [69]. Provided the necessary stimuli are present, DCs are probably the only antigen-presenting cells powerful enough to override this self-tolerance.

Besides asthma and COPD, the lung is also the stage for other chronic, often debilitating immunopathologies such as interstitial pneumonitis/fibrosis, vasculitis (e.g. Churg-Strauss, Wegener disease) and granulomatous inflammation (e.g. sarcoidosis, Langerhans cell histiocytosis). The etiology of these diseases is still obscure, and it remains to be examined whether airborne anthropogenic xenobiotics, by acting on pulmonary DCs, could provide the necessary spark to initiate an aberrant immune response in predisposed individuals.

\section{Conclusion}

In summary, it appears increasingly evident that the pulmonary innate immune system is a critical target of airborne xenobiotics. The large amount of experimental data available reflects the complex nature of these manmade compounds in terms of triggering specific innate molecular responses. Diverging effects are observed depending on co-existing stimuli and the cellular and tissue context. Nevertheless, it is worth noting that classical pathogen-associated molecules and human-made xenobiotics can use common sets of innate receptors such as TLRs and presumably inflammasome components. Even more intriguing is the way the aryl hydrocarbon receptor system and the cellular response to oxidative stress interconnect with immunological pathways. In this review, we provided evidence that molecular responses to xenobiotics can operate at the level of the dendritic cell. Given the extensive network of DCs in the airways, and the pivotal role of these cells in linking innate and adaptive immunity, we believe intensive preclinical and translational research in this field may produce unexpected insights in many pulmonary immunopathologies.

\section{Acknowledgments}

E. Lanckacker and L. Robays are supported by grants from the Concerted Research Initiative, Ghent University (BOF/ GOA 12050698 and BOF/GOA 12.515.04), Interuniversity Attraction Poles Program (Belgian State, Belgian Science Policy, Project P6/35) and Research Foundation - Flanders (Project 3G.0052.06). 


\section{References}

1 Zaas AK, Schwartz DA: Innate immunity and the lung: defense at the interface between host and environment. Trends Cardiovasc Med 2005;15:195-202.

- Voss T, Eistetter H, Schafer KP, Engel J: Macromolecular organization of natural and recombinant lung surfactant protein SP 28-36. Structural homology with the complement factor C1q. J Mol Biol 1988;201:219-227.

3 Mizgerd JP: Acute lower respiratory tract infection. N Engl J Med 2008;358:716-727.

4 Lewtas J: Air pollution combustion emissions: characterization of causative agents and mechanisms associated with cancer, reproductive, and cardiovascular effects. $\mathrm{Mu}$ tat Res 2007;636:95-133.

5 Vermaelen K, Pauwels R: Pulmonary dendritic cells. Am J Respir Crit Care Med 2005; 172:530-551.

-6 Hammad H, Chieppa M, Perros F, Willart MA, Germain RN, Lambrecht BN: House dust mite allergen induces asthma via Tolllike receptor 4 triggering of airway structural cells. Nat Med 2009;15:410-416.

7 Willart MA, Lambrecht BN: The danger within: endogenous danger signals, atopy and asthma. Clin Exp Allergy 2009;39:12-19.

8 McWilliam AS, Nelson D, Thomas JA, Holt PG: Rapid dendritic cell recruitment is a hallmark of the acute inflammatory response at mucosal surfaces. J Exp Med 1994; 179:1331-1336.

-9 Vermaelen KY, Carro-Muino I, Lambrecht BN, Pauwels RA: Specific migratory dendritic cells rapidly transport antigen from the airways to the thoracic lymph nodes. J Exp Med 2001;193:51-60.

10 Akbari O, DeKruyff RH, Umetsu DT: Pulmonary dendritic cells producing IL-10 mediate tolerance induced by respiratory exposure to antigen. Nat Immunol 2001;2: 725-731.

- 11 Bleck B, Tse DB, Curotto de Lafaille MA, Zhang F, Reibman J: Diesel exhaust particleexposed human bronchial epithelial cells induce dendritic cell maturation and polarization via thymic stromal lymphopoietin. J Clin Immunol 2008;28:147-156.

-12 Sydbom A, Blomberg A, Parnia S, Stenfors N, Sandstrom T, Dahlen SE: Health effects of diesel exhaust emissions. Eur Respir J 2001; 17:733-746.

13 Rahman I: Oxidative stress, chromatin remodeling and gene transcription in inflammation and chronic lung diseases. J Biochem Mol Biol 2003;36:95-109.

14 Dianzani MU, Barrera G, Parola M: 4-Hydroxy-2,3-nonenal as a signal for cell function and differentiation. Acta Biochim Pol 1999;46:61-75.

15 Dianzani MU: 4-Hydroxynonenal and cell signalling. Free Radic Res 1998;28:553-560.
16 Parola M, Robino G, Marra F, Pinzani M, Bellomo G, Leonarduzzi G, Chiarugi P, Camandola S, Poli G, Waeg G, Gentilini P, Dianzani MU: HNE interacts directly with JNK isoforms in human hepatic stellate cells. J Clin Invest 1998;102:1942-1950.

-17 Schaur RJ, Dussing G, Kink E, Schauenstein E, Posch W, Kukovetz E, Egger G: The lipid peroxidation product 4-hydroxynonenal is formed by - and is able to attract - rat neutrophils in vivo. Free Radic Res 1994;20:365373.

18 Lee H, Shi W, Tontonoz P, Wang S, Subbanagounder G, Hedrick CC, Hama S, Borromeo C, Evans RM, Berliner JA, Nagy L: Role for peroxisome proliferator-activated receptor alpha in oxidized phospholipid-induced synthesis of monocyte chemotactic protein1 and interleukin- 8 by endothelial cells. Circ Res 2000;87:516-521.

19 Matata BM, Galinanes M: Peroxynitrite is an essential component of cytokines production mechanism in human monocytes through modulation of nuclear factor-kappa B DNA binding activity. J Biol Chem 2002; 277:2330-2335.

20 Zhang P, Wang YZ, Kagan E, Bonner JC: Peroxynitrite targets the epidermal growth factor receptor, Raf- 1 , and MEK independently to activate MAPK. J Biol Chem 2000;275: 22479-22486.

21 Ito K, Hanazawa T, Tomita K, Barnes PJ, Adcock IM: Oxidative stress reduces histone deacetylase 2 activity and enhances IL- 8 gene expression: role of tyrosine nitration. Biochem Biophys Res Commun 2004;315: 240-245.

22 Rahman I, Adcock IM: Oxidative stress and redox regulation of lung inflammation in COPD. Eur Respir J 2006;28:219-242.

23 Cho HY, Jedlicka AE, Reddy SP, Kensler TW, Yamamoto M, Zhang LY, Kleeberger SR: Role of NRF2 in protection against hyperoxic lung injury in mice. Am J Respir Cell Mol Biol 2002;26:175-182.

24 McMahon M, Itoh K, Yamamoto M, Hayes JD: Keap1-dependent proteasomal degradation of transcription factor Nrf2 contributes to the negative regulation of antioxidant response element-driven gene expression. J Biol Chem 2003;278:21592-21600.

25 Dostert C, Petrilli V, Van BR, Steele C, Mossman BT, Tschopp J: Innate immune activation through Nalp3 inflammasome sensing of asbestos and silica. Science 2008;320:674677.

26 Williams MA, Rangasamy T, Bauer SM, Killedar S, Karp M, Kensler TW, Yamamoto M, Breysse P, Biswal S, Georas SN: Disruption of the transcription factor Nrf2 promotes pro-oxidative dendritic cells that stimulate Th2-like immunoresponsiveness upon activation by ambient particulate matter. J Immunol 2008;181:4545-4559.
27 Preynat-Seauve O, Coudurier S, Favier A, Marche PN, Villiers C: Oxidative stress impairs intracellular events involved in antigen processing and presentation to T cells. Cell Stress Chaperones 2003;8:162-171.

28 Kantengwa S, Jornot L, Devenoges C, Nicod LP: Superoxide anions induce the maturation of human dendritic cells. Am J Respir Crit Care Med 2003;167:431-437.

29 Rutault K, Alderman C, Chain BM, Katz DR: Reactive oxygen species activate human peripheral blood dendritic cells. Free Radic Biol Med 1999;26:232-238.

30 Matos TJ, Duarte CB, Goncalo M, Lopes MC: Role of oxidative stress in ERK and p38 MAPK activation induced by the chemical sensitizer DNFB in a fetal skin dendritic cell line. Immunol Cell Biol 2005;83:607-614.

31 Arrighi JF, Rebsamen M, Rousset F, Kindler V, Hauser C: A critical role for p38 mitogenactivated protein kinase in the maturation of human blood-derived dendritic cells induced by lipopolysaccharide, TNF-alpha and contact sensitizers. J Immunol 2001;166: 3837-3845.

32 Tan PH, Sagoo P, Chan C, Yates JB, Campbell J, Beutelspacher SC, Foxwell BM, Lombardi G, George AJ: Inhibition of NF-kappa B and oxidative pathways in human dendritic cells by antioxidative vitamins generates regulatory $\mathrm{T}$ cells. J Immunol 2005; 174:76337644.

33 Vassallo R, Kroening PR, Parambil J, Kita H: Nicotine and oxidative cigarette smoke constituents induce immune-modulatory and pro-inflammatory dendritic cell responses. Mol Immunol 2008;45:3321-3329.

34 Kroening PR, Barnes TW, Pease L, Limper A, Kita H, Vassallo R: Cigarette smoke-induced oxidative stress suppresses generation of dendritic cell IL-12 and IL-23 through ERK-dependent pathways. J Immunol 2008; 181:1536-1547.

35 Rangasamy T, Guo J, Mitzner WA, Roman J, Singh A, Fryer AD, Yamamoto M, Kensler TW, Tuder RM, Georas SN, Biswal S: Disruption of Nrf2 enhances susceptibility to severe airway inflammation and asthma in mice. J Exp Med 2005;202:47-59.

36 Kirkham P, Rahman I: Oxidative stress in asthma and COPD: antioxidants as a therapeutic strategy. Pharmacol Ther 2006;111: 476-494.

37 Ito K, Ito M, Elliott WM, Cosio B, Caramori G, Kon OM, Barczyk A, Hayashi S, Adcock IM, Hogg JC, Barnes PJ: Decreased histone deacetylase activity in chronic obstructive pulmonary disease. N Engl J Med 2005;352: 1967-1976.

- 38 Brogdon JL, Xu Y, Szabo SJ, An S, Buxton F, Cohen D, Huang Q: Histone deacetylase activities are required for innate immune cell control of Th1 but not Th2 effector cell function. Blood 2007;109:1123-1130. 
-39 Bode KA, Schroder K, Hume DA, Ravasi T, Heeg K, Sweet MJ, Dalpke AH: Histone deacetylase inhibitors decrease Toll-like receptor-mediated activation of proinflammatory gene expression by impairing transcription factor recruitment. Immunology 2007; 122:596-606.

-40 Wang B, Morinobu A, Horiuchi M, Liu J, Kumagai S: Butyrate inhibits functional differentiation of human monocyte-derived dendritic cells. Cell Immunol 2008;253:5458.

-41 Dong X, Lutz W, Schroeder TM, Bachman LA, Westendorf JJ, Kumar R, Griffin MD: Regulation of relB in dendritic cells by means of modulated association of vitamin $\mathrm{D}$ receptor and histone deacetylase 3 with the promoter. Proc Natl Acad Sci USA 2005;102: 16007-16012.

-42 Paul-Clark MJ, McMaster SK, Sorrentino R, Sriskandan S, Bailey LK, Moreno L, Ryffel B, Quesniaux VF, Mitchell JA: Toll-like receptor 2 is essential for the sensing of oxidants during inflammation. Am J Respir Crit Care Med 2009;179:299-306.

-43 Maes T, Bracke KR, Vermaelen KY, Demedts IK, Joos GF, Pauwels RA, Brusselle GG: Murine TLR4 is implicated in cigarette smokeinduced pulmonary inflammation. Int Arch Allergy Immunol 2006;141:354-368.

-44 Doz E, Noulin N, Boichot E, Guenon I, Fick L, Le BM, Lagente V, Ryffel B, Schnyder B, Quesniaux VF, Couillin I: Cigarette smokeinduced pulmonary inflammation is TLR4/ MyD88 and IL-1R1/MyD88 signaling dependent. J Immunol 2008;180:1169-1178.

$\checkmark 45$ Denison MS, Nagy SR: Activation of the aryl hydrocarbon receptor by structurally diverse exogenous and endogenous chemicals. Annu Rev Pharmacol Toxicol 2003;43:309334.

-46 Stevens EA, Mezrich JD, Bradfield CA: The aryl hydrocarbon receptor: a perspective on potential roles in the immune system. Immunology 2009;127:299-311.

-47 Schmidt JV, Bradfield CA: Ah receptor signaling pathways. Annu Rev Cell Dev Biol 1996;12:55-89.

48 Taylor MJ, Lucier GW, Mahler JF, Thompson M, Lockhart AC, Clark GC: Inhibition of acute TCDD toxicity by treatment with antitumor necrosis factor antibody or dexamethasone. Toxicol Appl Pharmacol 1992; 117:126-132.

49 Fan F, Yan B, Wood G, Viluksela M, Rozman KK: Cytokines (IL-1beta and TNFalpha) in relation to biochemical and immunological effects of 2,3,7,8-tetrachlorodibenzo-p-dioxin (TCDD) in rats. Toxicology 1997;116: 9-16.
50 Vogel C, Schuhmacher US, Degen GH, Bolt HM, Pineau T, Abel J: Modulation of prostaglandin $\mathrm{H}$ synthase-2 mRNA expression by 2,3,7,8-tetrachlorodibenzo-p-dioxin in mice. Arch Biochem Biophys 1998;351:265271.

51 Kerkvliet NI: Immunological effects of chlorinated dibenzo-p-dioxins. Environ Health Perspect 1995;103(suppl 9):47-53.

52 Head JL, Lawrence BP: The aryl hydrocarbon receptor is a modulator of anti-viral immunity. Biochem Pharmacol 2009;77:642653.

53 Lawrence BP, Roberts AD, Neumiller JJ, Cundiff JA, Woodland DL: Aryl hydrocarbon receptor activation impairs the priming but not the recall of influenza virus-specific CD8+ T cells in the lung. J Immunol 2006; 177:5819-5828.

54 Myers MJ, Schook LB, Bick PH: Mechanisms of benzo(a)pyrene-induced modulation of antigen presentation. J Pharmacol Exp Ther 1987;242:399-404.

55 van GJ, Rion S, Le FE, Le VM, Amiot L, Fauchet R, Fardel O: Polycyclic aromatic hydrocarbons inhibit differentiation of human monocytes into macrophages. J Immunol 2003;170:2374-2381.

-56 Jux B, Kadow S, Esser C: Langerhans cell maturation and contact hypersensitivity are impaired in aryl hydrocarbon receptor-null mice. J Immunol 2009;182:6709-6717.

57 Laupeze B, Amiot L, Sparfel L, Le FE, Fauchet R, Fardel O: Polycyclic aromatic hydrocarbons affect functional differentiation and maturation of human monocyte-derived dendritic cells. J Immunol 2002;168:26522658.

58 Platzer B, Richter S, Kneidinger D, Waltenberger D, Woisetschlager M, Strobl H: Aryl hydrocarbon receptor activation inhibits in vitro differentiation of human monocytes and Langerhans dendritic cells. J Immunol 2009; 183:66-74.

59 Lawrence BP, Denison MS, Novak H, Vorderstrasse BA, Harrer N, Neruda W, Reichel C, Woisetschlager M: Activation of the aryl hydrocarbon receptor is essential for mediating the anti-inflammatory effects of a novel low-molecular-weight compound. Blood 2008;112:1158-1165.
60 Hwang JA, Lee JA, Cheong SW, Youn HJ, Park JH: Benzo(a)pyrene inhibits growth and functional differentiation of mouse bone marrow-derived dendritic cells. Downregulation of RelB and eIF3 p170 by benzo(a)pyrene. Toxicol Lett 2007;169:82-90.

61 Lee JA, Hwang JA, Sung HN, Jeon CH, Gill BC, Youn HJ, Park JH: 2,3,7,8-Tetrachlorodibenzo-p-dioxin modulates functional differentiation of mouse bone marrow-derived dendritic cells. Downregulation of RelB by 2,3,7,8-tetrachlorodibenzo-p-dioxin. Toxicol Lett 2007;173:31-40.

62 Vogel CF, Goth SR, Dong B, Pessah IN, Matsumura F: Aryl hydrocarbon receptor signaling mediates expression of indoleamine 2,3-dioxygenase. Biochem Biophys Res Commun 2008;375:331-335.

63 Vogel CF, Sciullo E, Li W, Wong P, Lazennec G, Matsumura F: RelB, a new partner of aryl hydrocarbon receptor-mediated transcription. Mol Endocrinol 2007;21:2941-2955.

64 Lind EF, Ahonen CL, Wasiuk A, Kosaka Y, Becher B, Bennett KA, Noelle RJ: Dendritic cells require the NF-kappaB2 pathway for cross-presentation of soluble antigens. J Immunol 2008;181:354-363.

65 Eisenbarth SC, Piggott DA, Huleatt JW, Visintin I, Herrick CA, Bottomly K: Lipopolysaccharide-enhanced, toll-like receptor 4-dependent Thelper cell type 2 responses to inhaled antigen. J Exp Med 2002;196:16451651.

66 Robays LJ, Lanckacker EA, Moerloose KB, Maes T, Bracke KR, Brusselle GG, Joos GF, Vermaelen KY: Concomitant inhalation of cigarette smoke and aerosolized protein activates airway dendritic cells and induces allergic airway inflammation in a TLR-independent way. J Immunol 2009;183:27582766.

67 Robays LJ, Maes T, Joos GF, Vermaelen KY: Between a cough and a wheeze: dendritic cells at the nexus of tobacco smoke-induced allergic airway sensitization. Mucosal Immunol 2009;2:206-219.

68 Tsoumakidou M, Demedts IK, Brusselle GG, Jeffery PK: Dendritic cells in chronic obstructive pulmonary disease: new players in an old game. Am J Respir Crit Care Med 2008;177:1180-1186.

-69 Lee SH, Goswami S, Grudo A, Song LZ, Bandi V, Goodnight-White S, Green L, HackenBitar J, Huh J, Bakaeen F, Coxson HO, Cogswell S, Storness-Bliss C, Corry DB, Kheradmand F: Antielastin autoimmunity in tobacco smoking-induced emphysema. Nat Med 2007;13:567-569. 